\title{
Surveillance of Hemodialysis Vascular Access with Ultrasound Vector Flow Imaging
}

Brandt, Andreas Hjelm; Olesen, Jacob Bjerring; Lindskov Hansen, Kristoffer; Rix, Marianne; Jensen, Jørgen Arendt; Nielsen, Michael Bachmann

\section{Published in:}

Proceedings of SPIE

Link to article, DOI:

$10.1117 / 12.2081372$

Publication date:

2015

Document Version

Publisher's PDF, also known as Version of record

Link back to DTU Orbit

Citation (APA):

Brandt, A. H., Olesen, J. B., Lindskov Hansen, K., Rix, M., Jensen, J. A., \& Nielsen, M. B. (2015). Surveillance of Hemodialysis Vascular Access with Ultrasound Vector Flow Imaging. In J. G. Bosch, \& N. Duric (Eds.),

Proceedings of SPIE (Vol. 9419). [94190U] SPIE - International Society for Optical Engineering. Proceedings of SPIE - The International Society for Optical Engineering https://doi.org/10.1117/12.2081372

\section{General rights}

Copyright and moral rights for the publications made accessible in the public portal are retained by the authors and/or other copyright owners and it is a condition of accessing publications that users recognise and abide by the legal requirements associated with these rights.

- Users may download and print one copy of any publication from the public portal for the purpose of private study or research.

- You may not further distribute the material or use it for any profit-making activity or commercial gain

- You may freely distribute the URL identifying the publication in the public portal 


\title{
Surveillance of Hemodialysis Vascular Access with Ultrasound Vector Flow Imaging
}

\author{
Andreas Hjelm Brandt ${ }^{1 \mathrm{a}}$, Jacob Bjerring Olesen ${ }^{\mathrm{b}}$, Kristoffer Lindskov Hansen ${ }^{\mathrm{a}}$, Marianne Rix ${ }^{\mathrm{c}}$, \\ Jørgen Arendt Jensen ${ }^{\mathrm{b}}$, Michael Bachmann Nielsen ${ }^{\mathrm{a}}$ \\ ${ }^{a}$ Department of Radiology, Copenhagen University Hospital, Rigshospitalet, 2100 Copenhagen, \\ Denmark; ${ }^{\mathrm{b}}$ Center for Fast Ultrasound Imaging, Technical University of Denmark, 2800 Lyngby, \\ Denmark; ${ }^{\mathrm{C}}$ Department of Nephrology, Copenhagen University Hospital, Rigshospitalet, 2100 \\ Copenhagen, Denmark
}

\begin{abstract}
The aim of this study was prospectively to monitor the volume flow in patients with arteriovenous fistula (AVF) with the angle independent ultrasound technique Vector Flow Imaging (VFI). Volume flow values were compared with Ultrasound dilution technique (UDT). Hemodialysis patients need a well-functioning vascular access with as few complications as possible and preferred vascular access is an AVF. Dysfunction due to stenosis is a common complication, and regular monitoring of volume flow is recommended to preserve AVF patency. UDT is considered the gold standard for volume flow surveillance, but VFI has proven to be more precise, when performing single repeated instantaneous measurements. Three patients with AVF were monitored with UDT and VFI monthly for five months. A commercial ultrasound scanner with a $9 \mathrm{MHz}$ linear array transducer with integrated VFI was used to obtain data. UDT values were obtained with Transonic HD03 Flow-QC Hemodialysis Monitor. Three independent measurements at each scan session were obtained with UDT and VFI each month. Average deviation of volume flow between UDT and VFI was $25.7 \%(\mathrm{Cl}: 16.7 \%$ to $34.7 \%)(p=0.73)$. The standard deviation for all patients, calculated from the mean variance of each individual scan sessions, was $199.8 \mathrm{ml} / \mathrm{min}$ for UDT and $47.6 \mathrm{ml} / \mathrm{min}$ for VFI $(p=0.002)$. VFI volume flow values were not significantly different from the corresponding estimates obtained using UDT, and VFI measurements were more precise than UDT. The study indicates that VFI can be used for surveillance of volume flow.
\end{abstract}

Keywords: Vector flow imaging, Arteriovenous fistula, Volume flow surveillance

\section{INTRODUCTION}

The increasing number of patients with diabetes mellitus and elderly patients with vascular disease, increase the amount of patients dependent on hemodialysis (HD). ${ }^{1,2}$ HD patients need a well-functioning vascular access with constant delivery of blood flow to the dialysis machine and a low complication rate. A well-functioning vascular access is strongly associated with adequate dialysis and prolonged patient survival. ${ }^{3}$ The arteriovenous fistula (AVF) provides the best possible vascular access for HD, since it is sustainable and has fewer causes complications compared to other vascular access such as arteriovenous graft or central venous catheter. ${ }^{3,4}$

The AVF is a surgical created connection between an artery and a vein (Fig. 1). The new shaped circuit, leads to thickening and dilation of a superficial vein that is ideal for repeated needle insertions for HD treatment (Fig 2). The AVF is often created at the forearm, but can also be prepared at the upper arm. ${ }^{5}$ Even though the AVF is the vascular access with fewest complications, up to $60 \%$ of patients with AVF will experience dysfunction during the first 18 months after surgical creation. ${ }^{6}$ The main reason for dysfunction is stenosis. A stenosis increases intra-access pressure and decreases blood flow leading to thrombosis and ultimately loss of the AVF. ${ }^{6,7}$ Therefore, detection of stenosis and correction of angiographically significant stenosis before thrombosis occurs, is crucial. ${ }^{8}$

Further author information: Andreas Hjelm Brandt, email: andreas.hjelm.brandt@regionh.dk

Medical Imaging 2015: Ultrasonic Imaging and Tomography, edited by Johan G. Bosch, Neb Duric, Proc. of SPIE Vol. 9419, 94190U · (c) 2015 SPIE

CCC code: $1605-7422 / 15 / \$ 18 \cdot$ doi: $10.1117 / 12.2081372$

Proc. of SPIE Vol. 9419 94190U-1 
Currently, recommended guidelines for detection of vascular access dysfunction is regular clinical assessment before and after cannulation. The clinical examination contains inspection for edema, hyperemia and skin condition, palpation for thrill and pulsation, ausculation for bruit, post-dialysis observation for presence of hematoma, presence of pain, length of time to hemostasis, and registration of the nature of of the thrill and bruit. Furthermore, it is recommended to compliment the clinical assessment with venous pressure measurements, determination of recirculation and vascular access volume flow measurement. ${ }^{8}$ Adding vascular access flow to surveillance is associated with better detection and treatment of stenosis. ${ }^{9}$ Vascular access volume flow can be measured with spectral Doppler ultrasound and ultrasound dilution technique (UDT) ${ }^{10,11}$ UDT is considered the gold standard for volume flow surveillance of the AVF and has become the most widely used technique. ${ }^{12,13}$ Spectral Doppler ultrasound must be obtained with an insonating angle of 60 degrees or less to limit potential aspect of variability. ${ }^{14,15}$ However, this is challenging, since AVFs are parallel to the surface of the skin and thereby optimal scanned with an insonation angle of 90 degrees. ${ }^{16}$ Vector flow imaging (VFI) is a 2D angle independent technique for measuring velocity with ultrasound. ${ }^{17}$ VFI has recently shown to be applicable for volume flow measurements, and because of significantly lower standard deviation (SD) for single repeated instantaneous measurements, it is found to be more precise than UDT. ${ }^{16}$

The aim of this study is to use VFI as a technique for volume flow surveillance by prospectively monitoring the volume flow in patients with AVF using VFI and compared to UDT values. The hypothesis was to test if VFI performs equally good as UDT, and thus, can be used for surveillance of vascular access.

Figure 1: Illustration of an AVF.
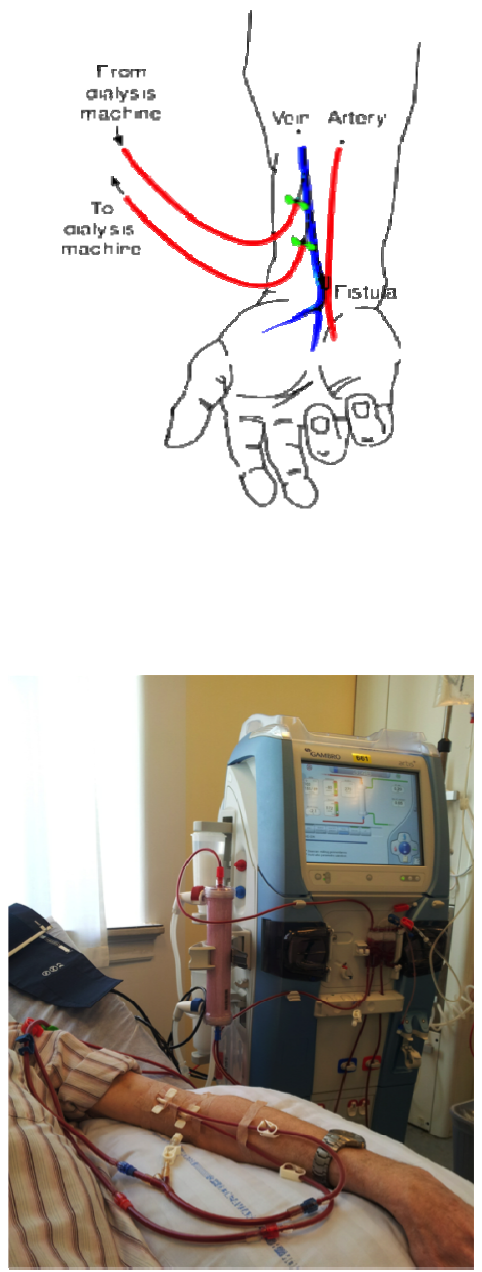

Figure 2: AVF connected to the dialysis machine. 


\section{METHOD}

\subsection{Patients}

Three patients (Patient 1: female 65 years, Patient 2: male 60 years, and Patient 3: male 56 years) with End Stage Renal Disease (ESRD) were enrolled from the Department of Nephrology. Inclusion criteria were stable HD for at least a period of four weeks and a matured/functional AVF. All patients were prospectively monitored with UDT and VFI monthly over a period of five months (scan session: time 0 - time 4). None of the patients needed corrective treatment with angioplasty or surgical revision during the observation period. Two patients had forearm AVF and one had upper arm AVF. All patients were included after written informed consent and after obtained approval by the Danish National Committee on Biomedical Research Ethics and the local Ethics Committee (journal no. H-4-2014-FSP).

\subsection{Scan Setup}

A commercial ultrasound scanner (UltraView 800, BK Medical, Herlev, Denmark) connected to a linear array transducer with a center frequency of $9 \mathrm{MHz}$ (8670, BK Medical, Herlev, Denmark) with integrated VFI was used for scanning. The VFI scan was performed prior to the dialysis and the patients were positioned in a bed or dialysis chair. The patients rested 10-15 min. before the scan, so the blood pressure and heart rate was in habitual level before the scan. An area with approximately laminar flow was sought located in the longitudinal direction and three recordings of 15 seconds were performed (Fig. 3). For each recording, pulse repetition frequency, depth and VFI gain was adjusted, thereby getting three independent VFI measurements of each patient to each scan session. For each recording, a corresponding VFI recording was performed in short axis view and the two perpendicular diameters of the vessel were measured (Fig 4). To ensure that the longitudinal VFI recording was from the center of the AVF, the transducer was positioned where the AVF had its widest diameter, and the innermost layer of the vessel was visible both at the top and bottom. All scans were performed with a minimum of pressure from the transducer on to the skin to avoid deformation of the AVF. Within an average of $26.6 \mathrm{~min}$ (range: 15-70 $\mathrm{min}$ ) after the VFI recording, UDT was measured. Three consecutive measurements were done with UDT. The UDT measurements were performed within an average of $8.1 \mathrm{~min}$ (range: 2-35 min) after the dialysis session had started.

\subsection{Volume flow with Vector Flow Imaging}

VFI is based on the Transverse Oscillation technique, which is an angle independent technique for vector velocity estimation with ultrasound ${ }^{18}$. VFI is FDA-approved and implemented on a commercial ultrasound scanner from BK Medical. Using VFI, the blood flow direction, magnitude and velocity is shown in 2D with color-coded pixels within a color box. To help interpret the flow profile, the scanner can superimpose arrows real-time on the color-coded pixels. The arrows indicate flow direction and velocity magnitude. Volume flow was calculated off-line using an in-house developed algorithm for MATLAB (MathWorks, Natick, MA, USA). The cross sectional area of the AVF is measured and the mean velocity is calculated from all the recorded VFI data. The mean velocity is calculated from the whole flow profile assuming that the profile is parabolic and circular symmetric. 225 frames of vector velocity frames corresponding to 15 seconds of data acquisition with a frame rate of $15 \mathrm{~Hz}$ were used for the volume flow estimation. The approach for volume flow calculation method is previously described by Hansen el. al. ${ }^{16}$

\subsection{Volume flow with Ultrasound dilution technique}

UDT is based on an indicator dilution method, where a known quantity of indicator substance (saline) is injected into the blood stream. The volume flow is found by measuring the change in blood concentration diluted by the indicator as a function of time. UDT is measured during dialysis by reversing blood lines. ${ }^{19}$ In this study the UDT measurements were performed using a Transonic HD03 Flow-QC Hemodialysis Monitor (Transonic Systems Inc., Ithaca, NY, USA), and all measurements were achieved by nurses with at least five years of experience with the Transonic system. The manufacturer expects for two consecutive measurements a variation of $100 \mathrm{ml} / \mathrm{min}$ with volume flow lower than $1000 \mathrm{ml} / \mathrm{min}$ and $10 \%$ expected variation with volume flows above $1000 \mathrm{ml} / \mathrm{min}$.

\subsection{Statistical analysis}

For descriptive analysis, the mean volume flow and standard deviation (SD) were calculated for all patients with both techniques. Deviation was calculated relative to the gold standard UDT and an unpaired t-test was applied for analyzing the difference in volume flow between VFI and UDT. The difference between the standard deviation for all patients, calculated by the mean variance for each of the individual scan sessions, was analyzed by an unpaired t-tested. Microsoft Excel (Redmond, WA, USA) and IBM SPSS statistics (Armonk, NY, USA) were applied for the statistical analysis. Statistical significance level was set at 0.05 . 


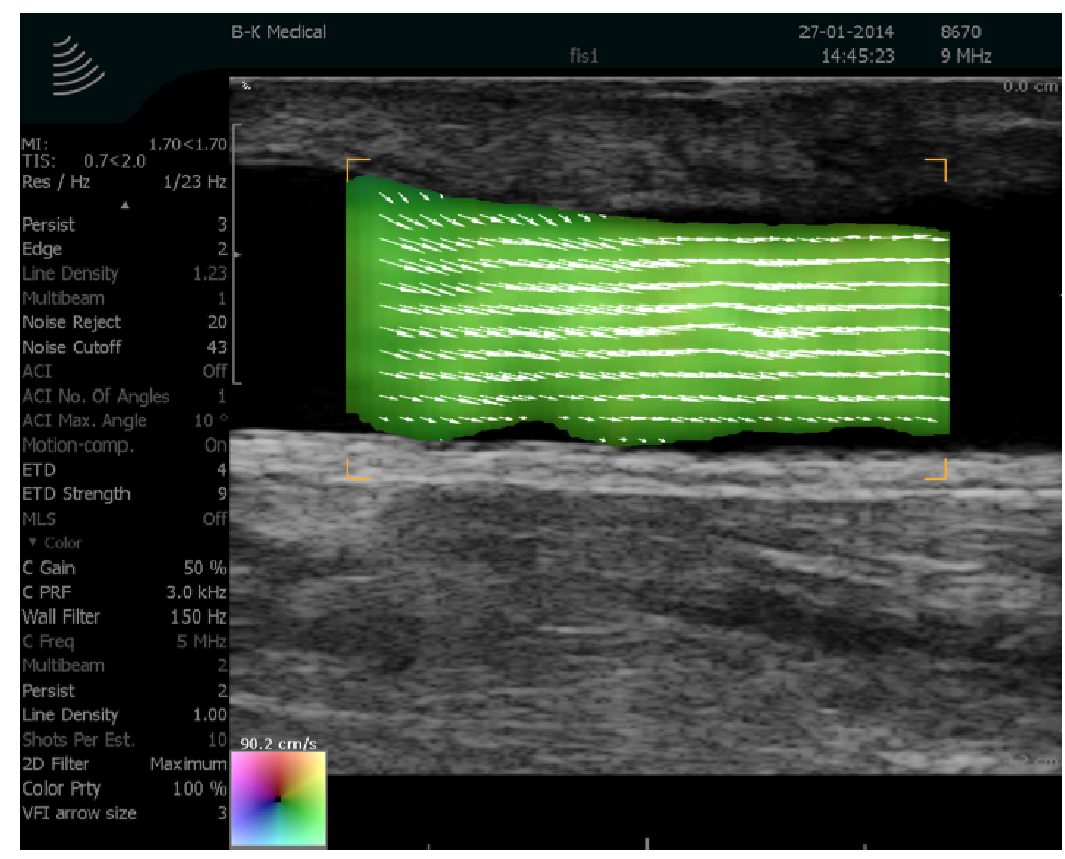

Figure 3: Longitudinal scan view of an AVF. The flow is laminar and parabolic with shorter arrows along the vessel walls, than centrally in the lumen of the vessel.

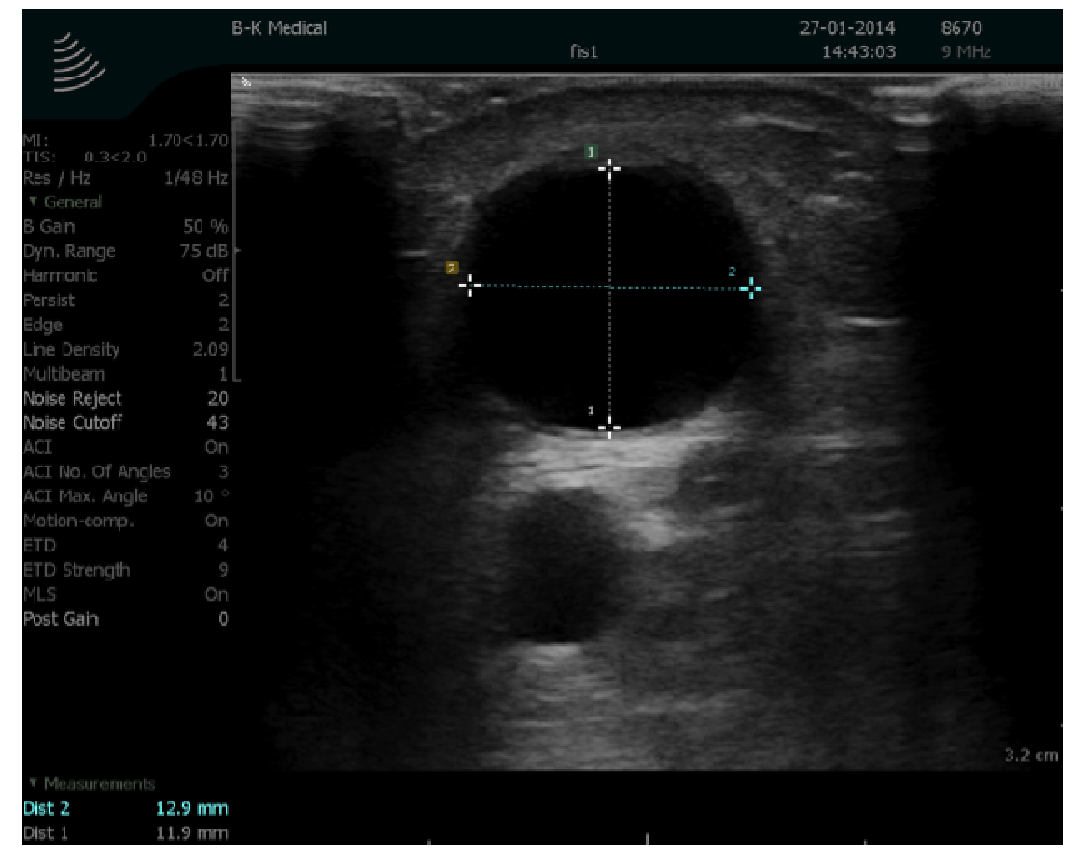

Figure 4: Transverse scan view of the AVF with perpendicular measurements of the diameter from inner edge to inner edge. 


\section{RESULTS}

Results from each single scan session and deviations are listed in Table 1. Average deviation of volume flow between UDT and VFI was $25.7 \%(\mathrm{Cl}: 16.7 \%$ to $34.7 \%, p=0.73)$. Deviation range was $2.1 \%-52.5 \%$.

The standard deviation for all patients, calculated by the mean variance for each of the individual scan sessions, was $199.8 \mathrm{ml} / \mathrm{min}$ with UDT and $47.6 \mathrm{ml} / \mathrm{min}$ with VFI, being significantly different $(p=0.002)$.

Table 1. Mean volume flow measurement with UDT and VFI. SD for each scan session is stated in brackets. Deviation and difference is calculated in reference to UDT.

\begin{tabular}{|c|c|c|c|c|}
\hline Patient 1 & Mean UDT (SD) ml/min & Mean VFI (SD) ml/min & Difference $\mathrm{ml} / \mathrm{min}$ & Deviation \% \\
\hline Time 0 & $640(43.6)$ & $449(54.8)$ & 191 & 29.8 \\
\hline Time 1 & $830(40.4)$ & $762(83.2)$ & 68 & 8.2 \\
\hline Time 2 & $836(47.3)$ & $1132(38.2)$ & -296 & -35.4 \\
\hline Time 3 & $736(40.4)$ & $591(12.3)$ & 145 & 19.7 \\
\hline Time 4 & $610(52.9)$ & $444(37.0)$ & 166 & 27.2 \\
\hline & & & & \\
\hline Patient 2 & Mean UDT (SD) ml/min & Mean VFI (SD) ml/min & & Deviation \% \\
\hline Time 0 & $1790(459)$ & $1753(78.8)$ & -89 & 2.1 \\
\hline Time 1 & $1903(190.9)$ & $1992(39.8)$ & -536 & -31.7 \\
\hline Time 2 & $1727(224.8)$ & $2263(51.0)$ & 857 & 49.8 \\
\hline Time 3 & $1720(525.7)$ & $863(40.3)$ & 191 & 9.1 \\
\hline Time 4 & $2103(61.1)$ & $1912(48.7)$ & & \\
\hline & & & -168 & -28.5 \\
\hline Patient 3 & Mean UDT (SD) ml/min & Mean VFI (SD) ml/min & 215 & 33.0 \\
\hline Time 0 & $590(45.8)$ & $758(8.7)$ & -163 & -47.0 \\
\hline Time 1 & $787(23.1)$ & $572(52.0)$ & -231 & -52.5 \\
\hline Time 2 & $347(30.6)$ & $510(84.9)$ & 87 & 12.6 \\
\hline Time 3 & $440(91.7)$ & $671(11.5)$ & $603(36.0)$ & \\
\hline Time 4 & $690(45.8)$ & & & \\
\hline
\end{tabular}

\section{DISCUSSIONS AND CONCLUSION}

The standard deviation of UDT was $199.8 \mathrm{ml} / \mathrm{min}$ and $47.6 \mathrm{ml} / \mathrm{min}$ for VFI, indicating more stable values with VFI $(p=$ 0.002). To minimize the hemodynamic variations during a dialysis sessions, it is recommended to analyze the blood flow in the beginning of the dialysis session, thereby, making measurements between sessions more comparable. ${ }^{20}$ The volume flow change between sessions is for clinical use the most interesting, since clinical decision of intervention is based on comparison between volume flow measurements during several dialysis sessions. Variance in needle placement, differences in hemodynamics, and vascular resistance in AVF, will cause larger variability in volume flow. ${ }^{21}$ Keeping this in mind, VFI with lower variation for volume flow measurements is therefore recommendable.

The volume flow average deviation between UDT and VFI was $25.7 \%$ based on three patients. Volume flow values between UDT and VFI were not significantly different. Due to change in hemodynamic variations and vascular resistance in the AVF at each dialysis session, the volume flow can vary considerably. Variations up to $40-50 \%$ have been reported. ${ }^{20}$ This implies that VFI can obtain satisfactory volume flow values for surveillance of AVF.

Blood volume flow measurement is a significant predictor of vascular access dysfunction in a AVF, and reduced flow indicates stenotic lesions anywhere in the circuit. ${ }^{3}$ Discovery of impending AVF failure by any method permits planned intervention with endovascular technique or open surgery and provides longer longevity of a matured AVF. ${ }^{22}$ Blood flow measurements can also be used to predict recurrent stenosis in hemodialysis AVF, which is considered a major problem. ${ }^{23}$ 
The advantage of ultrasound in monitoring AVFs compared to UDT is the noninvasive and painless examination, and the possibility of repeating the examination frequently, without the limitation of cannulation and attachment to the dialysis machine. The disadvantage of ultrasound is the operator dependency, and for conventional spectral Doppler ultrasound the low reproducibility reducing reliability. ${ }^{11,15}$ However, spectral Doppler ultrasound has been established to have a key role in management of hemodialysis vascular access. It is used to plan the construction of AVF by evaluating veins and arteries of the arm, and is considered a very important diagnostic tool together with the physical examination in the maturation period to check maturity parameters. It is also considered an important tool for surveillance, since it can provide information about access abnormalities, such as aneuryms, false aneuryms, and access induces ischemia. ${ }^{24}$

The advantage of VFI compared to conventional spectral Doppler technique is the angle independency, which makes it less operator dependent. ${ }^{16}$ AVFs can with VFI be scanned in their optimal position, where the angle of insonation is 90 degrees. The VFI can also give an immediate information on whether the flow is disturbed or laminar, as well as an assessment of where the velocities are highest. Compared to UDT, VFI can provide direct visualization of the AVF, thereby giving the option of evaluating for stenosis immediately and diagnosing complications such as hematoma, , aneuryms, and intraluminal thrombi. ${ }^{10}$

A limitation to VFI is the 2D image visualization. While doing a longitudinal scan, assessing whether the beam is at the center of the vessel or not, can be challenging to determine. Hitting slightly off the center causes the volume flow to be underestimated. Another limitation is the assumption that the vessel is circular. The AVF is a superficial vessel, thus, easily compressed under the weight of the transducer. ${ }^{25}$ This can change the geometry from circular to elliptical. However, UDT also has its limitations. The dialysis has to be initiated and the bloodlines have to be reversed before a flow can be obtained. This process takes time from the dialysis and is uncomfortable for both patient and dialysis nurse.

A larger study with more patients included is warranted to examine if VFI can replace UDT, as the preferred method for monitoring volume flow of AVF. This study indicates that VFI can estimate volume flow values, which are not significantly different from corresponding estimates obtained with golden standard UDT and that VFI is more precise than UDT.

\section{ACKNOWLEDGMENTS}

This work was supported by grant 82-2012-4 from the Danish Advanced Technology Foundation and BK Medical Aps, Denmark. Furthermore, we thank the helpful staff at the Department of Nephrology at Copenhagen University Hospital, Rigshospitalet, for their assistance in recruiting patients and helping during measurements.

\section{REFERENCES}

[1] Anand, S. , Kurella, T. M. and Chertow, G. M., "The elderly patients on hemodialysis," Minerva Urol Nefrol. 62(1), 87-101 (2010).

[2] Foley, R. N. and Collins, A. J., "The growing economic burden of diabetic kidney disease," Curr Diab Rep. 9(6), 460-5 (2009).

[3] Leivaditis K., Panagoutsos S., Roumeliotis A., Liakopoulos, V. and Vargemezis V., "Vascular access for hemodialysis: postoperative evaluation and function monitoring," Int Urol Nephrol. 46(2), 403-9 (2014).

[4] Rose, D. A., Sonaike, E. and Hughes, K., "Hemodialysis access," Surg Clin North Am. 93(4), 997-1012 (2013).

[5] Konner, K., Nonnast-Daniel, B. and Ritz, E., "The arteriovenous fistula," J Am Soc Nephrol. 14(6), 1669-80 (2003).

[6] Huijbregts, H. J., Bots, M. L., Wittens, C. H., Schrama, Y.C., Moll, F.L. and Blankestijn P.J., "Hemodialysis arteriovenous fistula patency revisited: results of a prospective, multicenter initiative," Clin J Am Soc Nephrol. 3(3), 714-9 (2008).

[7] Bittl, J. A., "Catheter interventions for hemodialysis fistulas and grafts," JACC Cardiovasc Interv. 3(1), 1-11 (2010).

[8] Vascular Access Work Group., "Clinical Practice Guidelines for Vascular Access," Am J Kidney Dis. 48, Supplement 1(0), S176-S247 (2006).

[9] Tessitore, N., Bedogna, V., Poli, A., Mantovani, W., Lipari, G., Baggio, E., Mansueto, G. and Lupo, A.,"Adding access blood flow surveillance to clinical monitoring reduces thrombosis rates and costs, and 
improves fistula patency in the short term: a controlled cohort study,” Nephrol Dial Transplant. 23(11), 3578-84 (2008).

[10] Whittier, W.L., "Surveillance of hemodialysis vascular access," Semin Intervent Radiol. 26(2), 130-8 (2009).

[11] Tessitore, N., Bedogna, V., Verlato, G. and Poli, A., "The rise and fall of access blood flow surveillance in arteriovenous fistulas," Semin Dial. 27(2), 108-18 (2014).

[12] Badr, B., Bories, P., Marais, R., Frat, B., Seigneuric, B., Longlune, N., Kamar, N., Maggioni, S. and Rostaing, L., "Transonic, thermodilution, or ionic dialysance to manage vascular access: which method is best?," Hemodial Int. 18(1), 127-35 (2014).

[13] Tessitore, N., Bedogna, V., Gammaro, L., Lipari, G., Poli, A., Baggio, E., Firpo, M., Morana, G., Mansueto, G. and Maschio, G., "Diagnostic accuracy of ultrasound dilution access blood flow measurement in detecting stenosis and predicting thrombosis in native forearm arteriovenous fistulae for hemodialysis," Am J Kidney Dis. 42(2), 331-41 (2003).

[14] Pedersen, M. M., Pihl, M. J., Haugaard, P., Hansen, J. M., Hansen, K. L., Nielsen, M. B. and Jensen, J. A., "Comparison of real-time in vivo spectral and vector velocity estimation, " Ultrasound Med Biol. 38(1), 145-51 (2012).

[15] Wiese, P. and Nonnast-Daniel, B., "Colour Doppler ultrasound in dialysis access," Nephrol Dial Transplant. 19(8), 1956-63 (2004).

[16] Hansen, P. M., Olesen, J. B, Pihl, M. J., Lange, T., Heerwagen, S., Pedersen, M. M., Rix, M., Lönn, L., Jensen, J. A. and Nielsen, M. B., "Volume flow in arteriovenous fistulas using vector velocity ultrasound," Ultrasound Med Biol. 40(11), 2707-14 (2014).

[17] Jensen, J. A., "Estimation of Blood Velocities Using Ultrasound: A Signal Processing Approach," Cambridge University Press. (1996).

[18] Jensen, J. A. and Munk, P., "A new method for estimation of velocity vectors," IEEE Trans Ultrason Ferroelectr Freq Control. 45(3), 837-51 (1998).

[19] Krivitski, N. M., "Theory and validation of access flow measurement by dilution technique during hemodialysis," Kidney Int. 48(1), 244-50 (1995).

[20] Paulson, W. D., Moist, L. and Lok, C. E., " Vascular access surveillance: an ongoing controversy," Kidney Int. 81(2), 132-42 (2012).

[21] Huisman, R. M., van Dijk, M., de Bruin, C., Loonstra, J., Sluiter, W. J., Zeebregts, C. J. and van den Dungen, J. J., "Within-session and between-session variability of haemodialysis shunt flow measurements," Nephrol Dial Transplant. 20(12), 2842-7 (2005).

[22] Surlan, M., Popovic, P., "The role of interventional radiology in management of patients with end-stage renal disease," Eur J Radiol. 46(2), 96-114 (2003).

[23] Mallios, A., Costanzo, A., Boura, B., Combes, M., Alomran, F., de Blic, R. and Jennings, W. C., "Long-term preservation of native arteriovenous dialysis fistulas," Ann Vasc Surg. 28(3), 749-55 (2014).

[24] Lomonte, C., Meola, M., Petrucci, I., Casucci, F. and Basile C., "The Key Role of Color Doppler Ultrasound in the Work-up of Hemodialysis Vascular Access," Semin Dial. (2014).

[25] Jensen, J., Olesen, J. B., Hansen, P. M., Nielsen, M. B. and Jensen, J. A., "Accuracy and Sources of Error for an Angle Independent Volume Flow Estimator," Proc. of IEEE International Ultrasonics Symposium (IUS). 17141717 (Oct 2014). 